High efficiency and high modal gain InAs/InGaAs/GaAs quantum dot lasers emitting at 1300 $\mathrm{nm}$

This content has been downloaded from IOPscience. Please scroll down to see the full text. 2007 Semicond. Sci. Technol. 22396

(http://iopscience.iop.org/0268-1242/22/4/017)

View the table of contents for this issue, or go to the journal homepage for more

Download details:

IP Address: 93.180.53.211

This content was downloaded on 27/01/2014 at 07:16

Please note that terms and conditions apply. 


\title{
High efficiency and high modal gain InAs/InGaAs/GaAs quantum dot lasers emitting at $1300 \mathrm{~nm}$
}

\author{
A Salhi, L Fortunato, L Martiradonna, M T Todaro, R Cingolani, \\ A Passaseo and M De Vittorio \\ National Nanotechnology Laboratory of CNR-INFM, Distretto tecnologico ISUFI, \\ Università di Lecce, 73100 Lecce, Italy \\ E-mail: abdelmajid.salhi@unile.it
}

Received 7 November 2006, in final form 20 January 2007

Published 9 March 2007

Online at stacks.iop.org/SST/22/396

\begin{abstract}
High performance $1300 \mathrm{~nm}$ lasers based on self-organized InAs/InGaAs quantum dots (QDs) are reported. By optimizing the QD growth parameters and decreasing the waveguide thickness, a high modal gain and a low transparency current density of $32 \mathrm{~cm}^{-1}$ and $35 \mathrm{~A} \mathrm{~cm}^{-2}$, respectively, were obtained from a device containing five stacked QD layers. The internal quantum efficiency is as high as $90 \%$.
\end{abstract}

\section{Introduction}

Semiconductor quantum dots (QDs) are a promising way for the realization of high performance laser diodes. Theoretical predictions of the intrinsic properties of QD lasers, such as strongly increased gain and differential gain, are expected to provide ultra-low threshold current density, large modulation bandwidth and high characteristic temperature $[1,2]$. The InAs/InGaAs/GaAs system has received a strong interest in the last few years. Room temperature continuous-wave operation lasers with high characteristic temperature, low threshold current density and high output power were reported [3-5]. However, in comparison with quantum well (QW) lasers, QD lasers still suffer from a low modal gain, which limits the modulation bandwidth and prevents the fabrication of short in-plane cavity devices. This limitation is due to both the low QD density and the small overlap of QD layers with the optical field. This problem is generally solved by stacking several QD layers and by carefully designing the laser structure, in particular the waveguide thickness. Moreover, the growth parameters should be optimized in order to preserve the same optical properties for each stacked layer.

In this work, we show that by growing highly uniform stack of QDs and by reducing the waveguide thickness, the modal gain can be increased up to $32 \mathrm{~cm}^{-1}$ from five InAs/InGaAs QD layers. This modal gain of $6.4 \mathrm{~cm}^{-1}$ per QD layer, normalized to the quantum dot density, is, to our knowledge, the highest value obtained from the five QD layer semiconductor laser. The enhancement of the modal gain is accompanied by a decrease of the threshold and transparency current densities per QD layer down to 16 and $7 \mathrm{~A} \mathrm{~cm}^{-2}$, respectively.

\section{Experiment}

The samples investigated in this study were grown by solid source molecular beam epitaxy (MBE) on 2 inch In-free mounted (1 00 l 0 GaAs substrates in a RIBER COMPACT 21-T system equipped with a valved As cracker cell. The grown structures are as follows: a $200 \mathrm{~nm}$ thick n-type GaAs buffer, a $1.5 \mu \mathrm{m}$ thick $\mathrm{Al}_{0.4} \mathrm{Ga}_{0.6}$ As n-type $\left(5 \times 10^{17} \mathrm{~cm}^{-3}\right.$, $\mathrm{Si}$ ) cladding layer, an undoped active zone consisting of five stacked InAs $/ \operatorname{In}_{0.18} \mathrm{Ga}_{0.82}$ As QD layers spaced by four $40 \mathrm{~nm}$ thick GaAs electronic barriers and enclosed by 205, 105 and $55 \mathrm{~nm}$ thick GaAs spacers (for structures $\mathrm{A}, \mathrm{B}$ and $\mathrm{C}$, respectively), a $1.5 \mu \mathrm{m}$ thick p-type $\mathrm{Al}_{0.4} \mathrm{Ga}_{0.6} \mathrm{As}(2 \times$ $10^{18} \mathrm{~cm}^{-3}, \mathrm{Be}$ ) cladding layer and finally a $300 \mathrm{~nm} \mathrm{p}^{+}-\mathrm{GaAs}$ cap layer. Each dot layer consists of 2.8 monolayers (ML) of InAs grown on GaAs and is capped by $4 \mathrm{~nm} \mathrm{In}_{0.18} \mathrm{Ga}_{0.82} \mathrm{As}$. The use of InGaAs quantum well on the top of the QD layers provides a more efficient carrier capture to the QDs states. The indium containing layers and the first $5 \mathrm{~nm}$ thick GaAs layer were grown at low temperature, whereas the remaining $35 \mathrm{~nm}$ of GaAs barrier was grown at high temperature to avoid defects formation. More details concerning the growth can be found in [6]. The QD density measured by AFM on an uncapped sample is $3.2 \times 10^{10} \mathrm{~cm}^{-2}$ with size dispersion 


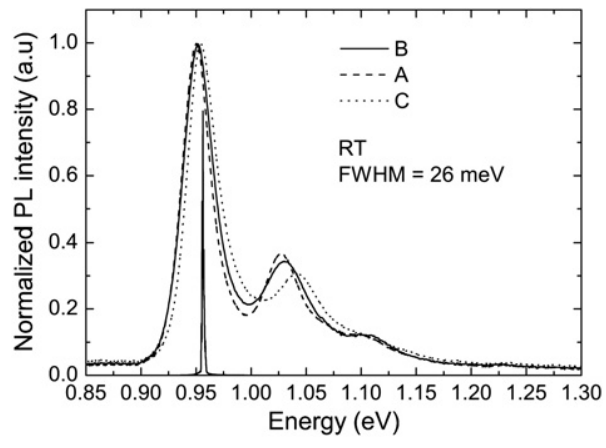

Figure 1. Photoluminescence emission at room temperature from unprocessed samples containing five stacked QD layers with different total active region thicknesses $(600,400$ and $300 \mathrm{~nm}$ for structures A, B and C, respectively). The ground state FWHM of all samples is $26 \mathrm{meV}$. The laser emission spectrum of a $1 \mathrm{~mm}$ cavity length device is also shown.

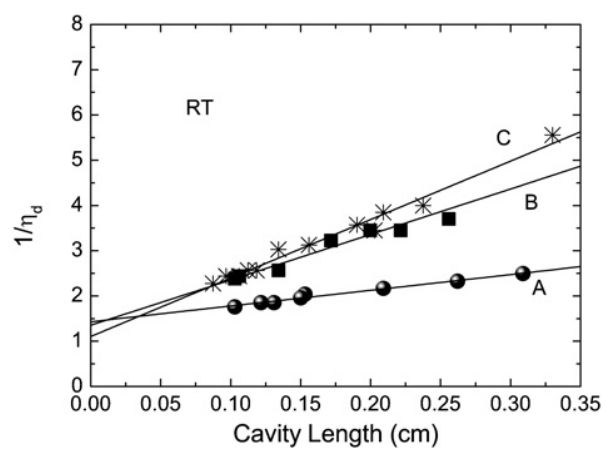

Figure 2. Reciprocal differential quantum efficiency of five QD layer laser devices as a function of the cavity length in the pulsed regime $(0.2 \%, 2 \mu \mathrm{s})$ and at room temperature for three structures with different total active region thicknesses $(600,400$ and $300 \mathrm{~nm}$ for structures A, B and C, respectively).

around $7 \%$. Both density and uniformity are preserved during stacking. Fabry-Perot lasers with $120 \mu \mathrm{m}$ wide metal contact stripes were fabricated from the grown wafer. The lasers with uncoated facets were tested at room temperature and in pulsed regime to avoid thermal effects.

\section{Results and discussion}

Figure 1 shows the photoluminescence (PL) emission from as-grown samples. The PL emission from the ground state is close to $1300 \mathrm{~nm}$ and the full width at half maximum (FWHM) of the ground state is $26 \mathrm{meV}$ for all the samples, indicating good size uniformity of QDs. We note that the energy difference between the two transitions is quite large, ranging from $79 \mathrm{meV}$ to $88 \mathrm{meV}$, due to the large size of the QDs and the low aspect ratio $(5 / 45=0.11)$. The laser emission of a $1 \mathrm{~mm}$ cavity length device at room temperature is also shown in figure 1 and is centred at $1307 \mathrm{~nm}$. Figure 2 shows the reciprocal differential quantum efficiency as a function of the cavity length for the three structures (structures $\mathrm{A}, \mathrm{B}$ and $\mathrm{C}$ ) with the total active region thicknesses of 600 , 400 and $300 \mathrm{~nm}$, respectively. Using a linear fitting, we have extracted the internal quantum efficiency $\eta_{\mathrm{i}}$ and the internal

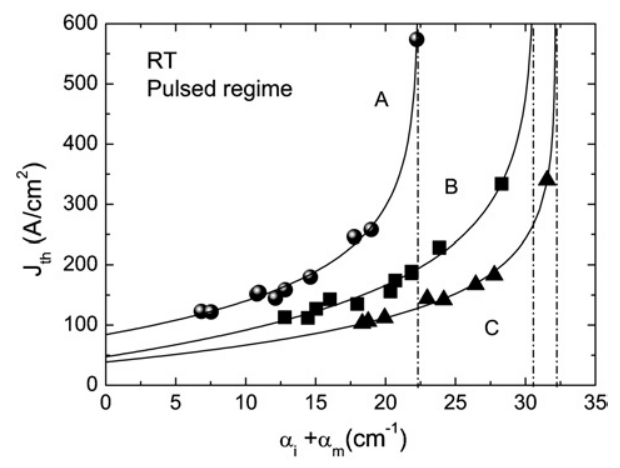

Figure 3. Threshold current density as a function of the total loss (modal gain at threshold) at room temperature and in the pulsed regime $(0.2 \%, 2 \mu \mathrm{s})$ of three laser structures with different total active region thickness and having five QD layers in the active region. Dashed lines indicate the saturation modal gain.

loss $\alpha_{\mathrm{i}}$ using the following relationship:

$$
\frac{1}{\eta_{\mathrm{d}}}=\frac{1}{\eta_{\mathrm{i}}}\left(1+\frac{\alpha_{\mathrm{i}}}{\alpha_{\mathrm{m}}}\right),
$$

where $\eta_{\mathrm{d}}$ is the external quantum efficiency and $\alpha_{\mathrm{m}}$ is the mirror loss given by $\frac{1}{L} \ln \left(\frac{1}{R}\right), L$ being the cavity length and $R$ the reflectivity of the laser facets. The external differential efficiency $\left(\eta_{\mathrm{d}}\right)$ was estimated from the room temperature lightcurrent characteristics measured on devices of different length. $\eta_{\mathrm{i}}$ is deduced for a cavity length equal to 0 . The values of $\alpha_{\mathrm{i}}$ and $\eta_{\mathrm{i}}$ for the three structures are summarized in table 1. $\eta_{\mathrm{i}}$ increases from $70 \%$ for structure $\mathrm{A}$ to $74 \%$ for structure B and it reaches a value as high as $90 \%$ for structure $\mathrm{C}$. As expected, the internal quantum efficiency is improved in thinner waveguide structures, because the probability of carrier capture into the QDs is higher and the non-radiative recombination rate is lower. The broadening of the waveguide can lead to a drastic reduction in the internal quantum efficiency due to the increased carrier density in the optical confinement layer of the optical waveguide as demonstrated in [7].

On the other hand, the internal losses are $\approx 3 \mathrm{~cm}^{-1}$, $9 \mathrm{~cm}^{-1}$ and $14 \mathrm{~cm}^{-1}$ for structures A, B and C, respectively. This result is mainly due to the enhancement of the free carrier absorption induced by the increased overlap of the evanescent field with the cladding layers, as the waveguide thickness is reduced. In fact, in our structures the cladding confinement factor increases from $\approx 12 \%$ for the structure $A$ to $\approx 25 \%$ for structure $\mathrm{B}$ and $\approx 38 \%$ for structure $\mathrm{C}$. By knowing the values of the internal losses for both structures, we have calculated the total losses $\alpha_{\mathrm{i}}+\alpha_{\mathrm{m}}$. In figure 3 we have plotted the threshold current density as a function of the total losses. The data were fitted by the empirical relationship

$$
J_{\text {th }}=J_{\text {tr }}+\frac{J_{\text {tr }}}{\gamma} \ln \left(\frac{g_{\text {sat }}}{g_{\text {sat }}-g_{\text {mod }}}\right),
$$

in which $J_{\text {th }}$ and $J_{\text {tr }}$ are the threshold and transparency current densities, respectively, $\gamma$ is a fitting parameter, $g_{\text {sat }}$ is the saturation modal gain and $g_{\bmod }$ is the modal gain [8]. $g$ mod is related to the material gain $G_{\mathrm{m}}$ by the relationship $g_{\bmod }=\Gamma_{\mathrm{QD}} \times G_{\mathrm{m}}$.

The saturation modal gain increases from $22 \mathrm{~cm}^{-1}$ (structure A) to $30 \mathrm{~cm}^{-1}$ (structure B) and $32 \mathrm{~cm}^{-1}$ (structure C). The increasing value of the modal gain can be explained 
Table 1. Internal losses, cladding confinement factor, internal quantum efficiency, QD confinement factor and the modal gain for the three QD laser structures.

\begin{tabular}{|c|c|c|c|c|c|c|}
\hline Structure & $\begin{array}{l}\text { Total active region } \\
\text { thickness }(\mathrm{nm})\end{array}$ & $\begin{array}{l}\text { Internal losses, } \\
\alpha_{\mathrm{i}}\left(\mathrm{cm}^{-1}\right)\end{array}$ & $\begin{array}{l}\text { Cladding confinement } \\
\text { factor }(\%)\end{array}$ & $\begin{array}{l}\text { Internal quantum } \\
\text { efficiency, } \eta_{\mathrm{i}}(\%)\end{array}$ & $\begin{array}{l}\text { QDs confinement } \\
\text { factor, } \Gamma_{\mathrm{QD}}(\%)\end{array}$ & $\begin{array}{l}\text { Modal gain, } \\
g_{\mathrm{m}}\left(\mathrm{cm}^{-1}\right)\end{array}$ \\
\hline $\mathrm{A}$ & 600 & 3 & 12 & 70 & 0.76 & 22 \\
\hline B & 400 & 9 & 25 & 74 & 0.87 & 30 \\
\hline $\mathrm{C}$ & 300 & 14 & 38 & 90 & 0.89 & 32 \\
\hline
\end{tabular}

mainly by the increasing value of the QD optical confinement factor $\Gamma_{\mathrm{QD}}$ which is estimated to be $0.76,0.87$ and $0.89 \%$ for structures A, B and C, respectively, as indicated in table 1. The QD optical confinement calculation was performed by considering the QD layer as a $\mathrm{QW}$ with equivalent thickness of $2.8 \mathrm{ML}$, which are the deposited monolayers of InAs. It is obvious that the obtained value is relatively lower than that of a classical QW with a typical thickness of 8-10 nm. Fray et al have reported a QD confinement factor of $0.17 \%$ for a single quantum dot layer, which is in good agreement with our calculation (0.76-0.89\% for five QD layers) [9].

As indicated previously, the modal gain increases with increasing internal losses. The highest modal gain per QD layer obtained from structure $\mathrm{C}$ is $6.4 \mathrm{~cm}^{-1}$, which to the best of our knowledge is the highest value for a multi-stacked QD laser emitting at $1300 \mathrm{~nm}$ with a comparable QD density. This value normalized to the QD density is twice the value obtained from a comparable semiconductor laser structure $\left(8.1 \mathrm{~cm}^{-1}\right)$ with a higher QD density of $8 \times 10^{10} \mathrm{~cm}^{-2}$ [10]. The high modal gain value validates the very good reproducibility of the optical properties and the good size uniformity of different QD layers in the stacked structure, and is also related to the relatively large energy difference between the ground and excited states. A modal gain per QD layer of 2.4 and $3.5 \mathrm{~cm}^{-1}$ was previously reported from laser structures containing ten QD layers [11,12]. The increased modal gain is accompanied by the reduction of the threshold and transparency current density. The transparency current densities per QD layer are 17, 9 and $7 \mathrm{~A} \mathrm{~cm}^{-2}$ and the threshold current densities for an infinite cavity length per QD layer are 19, 17 and $16 \mathrm{~A} \mathrm{~cm}^{-2}$.

The optimization of the growth parameters, to obtain a good size uniformity of the QDs with a large size and a high aspect ratio, and the use of a relatively large thick GaAs barriers allow the stacking of several QD layers in the same active region, preserving the same optical properties for the second and the subsequent layers. In addition, a reduction of the waveguide thickness is necessary in order to increase QD optical confinement and to consequently obtain a high modal gain. Structure $\mathrm{C}$ seems to give the best results in terms of modal gain and internal quantum efficiency. However, a higher internal loss value limits the external quantum efficiency for this sample. To decrease the internal losses by keeping a high value of the modal gain, a graded index separate confinement heterostructure (GRINSCH) could be used.

\section{Conclusion}

In conclusion, we demonstrated high performance laser devices containing five stacked QD layers. A modal gain of $32 \mathrm{~cm}^{-1}$ has been achieved at room temperature and at $1307 \mathrm{~nm}$; the transparency current density per QD layer was as low as $7 \mathrm{~A} \mathrm{~cm}^{-2}$. Internal quantum efficiency as high as $90 \%$ is obtained.

\section{Acknowledgments}

This work was supported by the national project 297-MIUR 'Nanotecnologie e materiali optoelettronici per applicazioni telecom e datacom'. The authors thank Gianmichele Epifani and Paolo Cazzato for their expert technical help.

\section{References}

[1] Asada M, Miyamoto Y and Suematsu Y 1986 Gain and the threshold of three dimensional quantum-box lasers IEEE J. Quantam Electron. 22 1915-21

[2] Arakawa Y and Sakaki H 1982 Multidimensional quantum well laser and temperature dependence of its threshold current Appl. Phys. Lett. 40 939-41

[3] Mikhrin S S et al 2005 High power temperature-insensitive $1.3 \mu \mathrm{m}$ InAs/InGaAs/GaAs quantum dot lasers Semicond. Sci. Technol. 20 340-42

[4] Liu H Y, Childs D T, Badcock T J, Groom K M, Sellers I R, Hopkinson M, Hogg R A, Robbins D J, Mowbray D J and Skolnick M S 2005 High-performance three-layer 1.3- $\mu \mathrm{m}$ InAs-GaAs quantum-dot lasers with very low continuous-wave room-temperature threshold currents IEEE Photonics Technol. Lett. 17 1139-41

[5] Wilk A, Kovsh A R, Mikhrin S S, Chaix C, Novikov I I, Maximov M V, Shernyakov Yu M, Ustinov V M and Ledentsov N N 2005 High-power $1.3 \mu \mathrm{m}$ InAs/GaInAs/GaAs QD lasers grown in a multiwafer MBE production system $J$. Cryst. Growth 278 335-41

[6] Salhi A, Martiradonna L, Visimberga G, Tasco V, Fortunato L, Todaro M T, Cingolani R, Passaseo A and De Vittorio M 2006 High-modal gain $1300 \mathrm{~nm} \mathrm{In}(\mathrm{Ga}) \mathrm{As} / \mathrm{GaAs}$ quantum dot lasers IEEE Photonics Technol. Lett. 18 1735-7

[7] Ryvkin B S and Avrutin E A 2005 Effect of carrier loss through waveguide layer recombination on the internal quantum efficiency in large-optical-cavity laser diodes J. Appl. Phys. 97113106

[8] Zhukov A E et al 1999 Gain characteristics of quantum dot injection lasers Semicond. Sci. Technol. 14 118-23

[9] Fry P W et al 2000 Modal gain and lasing states in InAs/GaAs self-organized quantum dot lasers J. Appl. Phys. 87 615-7

[10] Amano T, Sugaya T and Komori K 2006 1.3- $\mu$ m InAs quantum-dot laser with high dot density and high uniformity IEEE Photonics Technol. Lett. 18 619-21

[11] Zhukov A E et al 2003 High external differential efficiency and high optical gain of long-wavelength quantum dot diode laser Physica E 17 589-92

[12] Sugawara M, Hatori N, Ishida M, Ebe H, Arakawa Y, Akiyama T, Otsubo K, Yamamoto T and Nakata Y 2005 Recent progress in self-assembled quantum-dot optical devices for optical telecommunication: temperature-insensitive $10 \mathrm{~Gb} \mathrm{~s}^{-1}$ directly modulated lasers and $40 \mathrm{~Gb} \mathrm{~s}^{-1}$ signal-regenerative amplifiers J. Phys. D: Appl. Phys. 38 2126-34 